\title{
Neoadjuvant Radiotherapy Use in Locally Advanced Rectal Cancer at NCCN Member Institutions
}

\author{
Marsha Reyngold, MD, PhDª Joyce Niland, $\mathrm{PhD}^{\mathrm{b}}$; Anna ter Veer, $\mathrm{MS}^{\mathrm{c}}$; Dana Milne, $\mathrm{MA}^{\mathrm{d}}$;

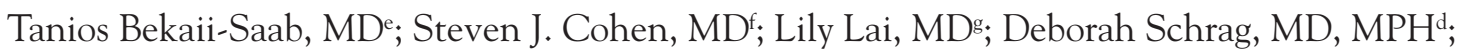 \\ John M. Skibber, MD' William Small Jr, MDi; Martin Weiser, MD; Neal Wilkinson, MD, MPH'; \\ and Karyn A. Goodman, MD, MS
}

\begin{abstract}
Based on randomized data, neoadjuvant chemoradiotherapy has been incorporated into the NCCN Clinical Practice Guidelines in Oncology (NCCN Guidelines) for stage II-III rectal cancer. Factors associated with nonadherence to evidence-based guidelines for neoadjuvant radiotherapy (RT) were examined at dedicated cancer centers. The prospective NCCN Oncology Outcomes Database for Colorectal Cancers was queried for patients with stage II-III rectal cancer who underwent a transabdominal surgical resection between September 2005 and June 2012. Multivariable logistic regression was used to identify factors associated with omission of RT. Among 1199 identified patients, 1119 (93\%) received neoadjuvant RT, 51 (4\%) did not receive RT, and 29 (2\%) received adjuvant RT. Among 51 patients not receiving RT, only 19 (37\%) were referred and evaluated by a radiation oncologist. On multivariable analysis, clinical factors associated with not receiving $\mathrm{RT}$ included a
\end{abstract}

history of prior pelvic RT (adjusted odds ratio [aOR], 23.9; $P=.0003$ ), ECOG performance status of 2 or greater (aOR, 11.1; $P=.01)$, tumor distance from the anal verge greater than $10 \mathrm{~cm}$ (aOR, 5.4; $P=.009$ ), age at diagnosis of 75 years or older ( $\mathrm{aOR}, 4.43 ; P=.002)$, body mass index of 25 to $30 \mathrm{~kg} / \mathrm{m}^{2}$ and less than $25 \mathrm{~kg} / \mathrm{m}^{2}$ (aOR, 5.22 and 4.23, respectively; $P=.03$ ), and clinical stage II (aOR, 2.27; $P=.02$ ). No significant change was seen in RT use according to diagnosis year, nor was any correlation seen with distance to the nearest RT facility. Concordance with NCCN Guidelines for neoadjuvant RT is high among NCCN Member Institutions. After adjusting for clinical characteristics that increase the risk for RT toxicity, including history of pelvic RT and high comorbidity burden/low functional status, the authors found that non-obese patients of advanced age or those with more favorable clinical features were more likely to not receive RT. (J Nat/ Compr Canc Netw 2014;12:235-243)

Preoperative chemoradiation followed by surgical resection has been the standard of care in the management of locally advanced rectal cancer. Patients with T3-T4 or node-positive disease have a significant risk of both local and distant failure after surgery alone. ${ }^{1}$ Initially, studies of radiotherapy (RT), either as postoperative or preoperative therapy, and more recently studies of combined modality therapy with radiation-sensitizing chemotherapy showed an improvement in local control and a reduction in anastomotic recurrences. ${ }^{2-9}$ This benefit persists in the era of total mesorectal excision (TME), ${ }^{3,10}$ To determine the optimal sequence for surgery and chemoradiation, a landmark German rectal study compared preoperative and postoperative 5-FUbased chemoradiotherapy in 823 patients. It showed improved local control, increased rates of sphincter preservation, and lower toxicity in patients receiving preoperative chemoradiation. ${ }^{11}$ 
Reyngold et al

Based on this trial, the current NCCN Clinical Practice Guidelines in Oncology (NCCN Guidelines) for locally advanced resectable rectal cancer include neoadjuvant RT with capecitabine or concurrent 5-FU infusion, followed by TME and an adjuvant course of consolidative chemotherapy (to view the most recent version of these guidelines, visit NCCN.org). ${ }^{12}$ The goal of evidence-based treatment guidelines is to decrease variability and improve the quality of cancer care. Adherence to practice guidelines is a useful indicator of quality of care. In particular, the NCCN/ASCO expert panel has recommended that receipt of pelvic RT for patients younger than 80 years with stage II-III rectal cancer within 6 months of diagnosis be included in the quality measures used in accountability programs. ${ }^{13}$ In addition to providing a measure of quality of care with regard to neoadjuvant RT in advanced rectal cancer, the NCCN Oncology Outcomes Database for Colorectal Cancers offers a unique opportunity to study factors associated with omission of RT. Clinical decision-making is a complex process that often involves subjective assessment of the potential risks and benefits associated with a given treatment. Using this database, the authors sought to elucidate the potential factors associated with nonadherence to the NCCN Guidelines recommendations regarding neoadjuvant RT for locally advanced rectal cancer.

\section{Materials and Methods}

\section{Data Source}

Data were acquired from the NCCN Colorectal Cancer Outcomes Database project, a prospective database of abstracted medical records from 8 participating NCCN Member Institutions: City of Hope Comprehensive Cancer Center; The Ohio State University Comprehensive Cancer Center - James Cancer Hospital and Solove Research Institute; Memorial Sloan-Kettering Cancer Center; The University of Texas MD Anderson Cancer Center; Dana-Farber Cancer Institute; Fox Chase Cancer Center; Roswell Park Cancer Center; and Robert H. Lurie Comprehensive Cancer Center of Northwestern University. Each is a major academic comprehensive cancer center with dedicated subspecialty and multidisciplinary expertise in colorectal cancer. The study data collection process, transmission methods, and storage protocols were approved by the institutions' respective Institutional Review Boards.
Sociodemographic status, insurance coverage, comorbidity, and physician-reported ECOG performance status were abstracted at each patient's first presentation. Comorbidity was assigned using the Charlson Comorbidity Index. ${ }^{14}$ The median household income in the zip code of each patient's residence was derived from the 2000 census data. The distance to the nearest radiation facility was calculated based on latitude and longitude of patients' residences, derived from ZIPList5 (Geocode Z5LLDOC.TXT, 1995-2002; www.zipinfo.com) and the latitude and longitude of 1197 hospitals and health care systems offering RT (excluding free-standing facilities not in a system or network), derived from the 2008 American Hospital Association Annual Survey of Hospitals. ${ }^{15}$ Patients' medical records were systematically reviewed at 4, 8, and 12 months after presentation, and annually thereafter, to capture treatment and recurrence data. Data were abstracted by NCCN-trained Clinical Research Assistants using structured forms.

\section{Patient Selection}

All NCCN-registered patients diagnosed with stage II-III rectal cancer who underwent a transabdominal resection at a participating institution between September 1, 2005, and June 15, 2012, were eligible $(n=2184)$. Exclusion criteria were as follows: rectosigmoid junction or synchronous colon and rectal tumors $(n=747)$, enrollment on an experimental protocol $(n=146)$, clinical stage at diagnosis other than stage II-III $(n=81)$, relapse or death within 120 days of diagnosis $(n=8)$, and incomplete adjuvant therapy data $(n=3)$. A total of 29 patients received postoperative RT and were excluded from the analysis of factors associated with omission of preoperative RT. The minimum follow-up time was 120 days for all patients.

\section{Variables Analyzed}

Demographic characteristics potentially associated with receipt of RT chosen for analysis included age at diagnosis, gender, racial/ethnic background, type of insurance (private, Medicare, Medicaid), household income, NCCN Member Institution, distance to the nearest RT facility, and year of diagnosis. Median household income and distance to the nearest RT facility were divided into quartiles. Clinical patient characteristics analyzed included body mass index [BMI], ECOG performance status, 
Charlson comorbidity score, history of inflammatory bowel disease (IBD), and history of pelvic RT for a prior cancer. Tumor characteristics included clinical TNM stage, preoperative tumor fixation, and tumor distance from the anal verge $(2 \mathrm{~cm}$ were added to the measurements from the dentate line).

\section{Statistical Analysis}

The primary end point of analysis was receipt of preoperative RT. The association between RT and patient characteristics was characterized using descriptive statistics. A simple Chi-square test for association was used to compare proportions between RT and no-RT groups. The association between nonreceipt of RT and each variable was assessed independently in a univariate logistic regression model. Parameters found to be potentially associated with no RT, based on a $P$ value of 0.20 or less, were included in the initial multivariable model. The final multivariable model included predictors with a 2 -sided $P$ value less than 0.05 , and the control variables were defined a priori $(\mathrm{NCCN}$ Member Institution, Charlson comorbidity score, and gender). Point estimates of the multivariable model were reported as adjusted odds ratios (aORs) and 95\% CIs with the 2 -sided $P$ value for each aOR. All statistical analyses were conducted using SAS software (SAS Institute Inc., Cary, NC).

\section{Results}

Among NCCN colorectal database-registered patients, 1199 patients with stage II-III rectal cancer met the inclusion criteria; 1119 patients (93\%) received preoperative RT, 51 (4\%) did not receive RT, and 29 (2\%) received postoperative RT. To identify factors associated with nonreceipt of preoperative RT, patients who did not receive RT were compared with those who received preoperative RT. These 1170 patients defined the study cohort and their baseline characteristics by receipt of preoperative RT are summarized in Table 1 . The median age was 58.5 years, and $116(10 \%)$ patients were 75 years or older. Most patients were Caucasian (85\%) with a slight male predominance $(59 \%)$. Most patients had ECOG performance status of 0 (81\%), no comorbidities (73\%), and stage III rectal cancer (64\%). Only 12 patients had a history of prior pelvic RT and $15 \mathrm{had}$ IBD; $50 \%$ lived within 5 miles of a radiation facility. More than $50 \%$ of patients were treated at 2 of 8 participating NCCN Member Institutions. With the exception of the first and last years of the study period, no significant variation was seen in the number of enrolled patients by year.

Compared with patients who received RT, those who did not were more likely to be older, have worse performance status, and have a higher comorbidity burden. They were also more likely to have Medicare versus private insurance or Medicaid and be treated at one NCCN Member Institution (Table 1). Chemotherapy was administered to $99 \%$ of patients receiving RT and only $53 \%$ of patients not receiving RT $(P<.0001)$. In the RT group, $21 \%$ received neoadjuvant chemotherapy only, $77 \%$ received both neoadjuvant and adjuvant, and $1 \%$ received adjuvant only. In contrast, among patients not receiving RT a larger percentage received chemotherapy adjuvantly: $8 \%$ of patients received neoadjuvant chemotherapy only, $24 \%$ received both neoadjuvant and adjuvant, and $21 \%$ received adjuvant only.

On multivariable analysis, clinical variables associated with not receiving RT included history of prior pelvic RT (adjusted OR [aOR], 23.9; $P=.0003$ ), ECOG performance status of 2 or greater $(\mathrm{aOR}$, $11.1 ; P=.01)$, age at diagnosis of 75 years or older (aOR, 4.43; $P=.002$ ), tumor distance from the anal verge greater than $10 \mathrm{~cm}(\mathrm{aOR}, 5.4 ; P=.009)$, BMI of 25 to $30 \mathrm{~kg} / \mathrm{m}^{2}$ and less than $25 \mathrm{~kg} / \mathrm{m}^{2}$ (aOR, 5.22 and 4.23, respectively; $P=.03$ ), and clinical stage II (aOR, 2.27; $P=.02$; Table 2). The association between age and omission of RT was evaluated by decade. Although only $3 \%$ or fewer of patients younger than 74 years did not receive neoadjuvant RT, this number increased to $17 \%$ in patients aged 75 years or older. A trend was also seen for higher Charlson comorbidity score and female sex among patients not receiving RT. Although some variability was noted in RT omission among different NCCN Member Institutions, it did not reach statistical significance. No significant change was seen in RT use according to diagnosis year or distance from the nearest RT facility. Race, median income, history of IBD, and preoperative tumor fixation were not associated with neoadjuvant RT use in this cohort.

Referral patterns were available for 50 of 51 patients not receiving RT. Among them, 29 (58\%) were not referred to a radiation oncologist, 19 (38\%) were referred and evaluated, and 2 (4\%) were referred but never evaluated. 
Reyngold et al

Table 1 Characteristics of 1170 Patients Undergoing Transabdominal Resection for Stage II-III Rectal Cancer at NCCN Cancer Centers (2005-2012), by Preoperative RT

\begin{tabular}{|c|c|c|c|c|c|}
\hline Variable & Category & $\begin{array}{l}\text { All Patients } \\
(n=1170)\end{array}$ & $\begin{array}{l}\text { Preoperative RT } \\
(n=1119)\end{array}$ & $\begin{array}{l}\text { No Preoperative } \\
\text { RT }(n=51)\end{array}$ & $P$ Value $^{a}$ \\
\hline \multicolumn{6}{|l|}{ Age at diagnosis, y } \\
\hline Median (range) & & $58.5(18-92)$ & $58.3(18-88)$ & $67.3(36-92)$ & \\
\hline \multirow[t]{5}{*}{ N (column \%) } & $<45$ & $189(16 \%)$ & $184(16 \%)$ & $5(10 \%)$ & $<.0001$ \\
\hline & $45-54$ & $291(25 \%)$ & $281(25 \%)$ & $10(20 \%)$ & \\
\hline & $55-64$ & $331(28 \%)$ & $321(29 \%)$ & $10(20 \%)$ & \\
\hline & $65-74$ & $243(21 \%)$ & $237(21 \%)$ & $6(12 \%)$ & \\
\hline & $\geq 75$ & $116(10 \%)$ & $96(9 \%)$ & $20(39 \%)$ & \\
\hline \multirow[t]{2}{*}{ Sex } & Male & $695(59 \%)$ & $671(60 \%)$ & $24(47 \%)$ & .07 \\
\hline & Female & $475(41 \%)$ & $448(40 \%)$ & $27(53 \%)$ & \\
\hline \multirow[t]{4}{*}{ Race } & Caucasian & $1000(85 \%)$ & $959(86 \%)$ & $41(80 \%)$ & .56 \\
\hline & African American & $77(7 \%)$ & $72(6 \%)$ & $5(10 \%)$ & \\
\hline & Asian, Pacific Islander & $70(6 \%)$ & $67(6 \%)$ & $3(6 \%)$ & \\
\hline & Other & $23(2 \%)$ & $21(2 \%)$ & $2(4 \%)$ & \\
\hline \multirow[t]{4}{*}{ Insurance type } & Private & $695(59 \%)$ & $673(60 \%)$ & $22(43 \%)$ & .02 \\
\hline & Medicare & $337(29 \%)$ & $314(28 \%)$ & $23(45 \%)$ & \\
\hline & Medicaid & $91(8 \%)$ & $89(8 \%)$ & $2(4 \%)$ & \\
\hline & Other & $47(4 \%)$ & $43(4 \%)$ & $4(8 \%)$ & \\
\hline \multicolumn{6}{|l|}{ Household Income in 1999} \\
\hline Median (range) & & $\begin{array}{l}\$ 47,181 \\
(\$ 9,400-\$ 141,592)\end{array}$ & $\begin{array}{l}\$ 46,885 \\
(\$ 9,400-\$ 141,592)\end{array}$ & $\begin{array}{l}\$ 55,869 \\
(\$ 26,931-\$ 101,868)\end{array}$ & \\
\hline \multirow[t]{5}{*}{ N (column \%) } & $<\$ 40,000$ & $402(34 \%)$ & $389(35 \%)$ & $13(25 \%)$ & .23 \\
\hline & $\$ 40,000-\$ 60,000$ & $378(32 \%)$ & $361(32 \%)$ & $17(33 \%)$ & \\
\hline & $\$ 60,000-\$ 80,000$ & $221(19 \%)$ & $206(18 \%)$ & $15(29 \%)$ & \\
\hline & $\geq \$ 80,000$ & $117(10 \%)$ & $111(10 \%)$ & $6(12 \%)$ & \\
\hline & Unknown & $52(4 \%)$ & $52(5 \%)$ & $0(0 \%)$ & \\
\hline \multirow[t]{8}{*}{ NCCN Member Institution } & 1 & $49(4 \%)$ & $43(4 \%)$ & $6(12 \%)$ & .05 \\
\hline & 2 & $95(8 \%)$ & $94(8 \%)$ & $1(2 \%)$ & \\
\hline & 3 & $58(5 \%)$ & $56(5 \%)$ & $2(4 \%)$ & \\
\hline & 4 & $273(23 \%)$ & $266(24 \%)$ & $7(14 \%)$ & \\
\hline & 5 & $51(4 \%)$ & $50(4 \%)$ & $1(2 \%)$ & \\
\hline & 6 & $124(11 \%)$ & $118(11 \%)$ & $6(12 \%)$ & \\
\hline & 7 & $426(36 \%)$ & $403(36 \%)$ & $23(45 \%)$ & \\
\hline & 8 & $94(8 \%)$ & $89(8 \%)$ & $5(10 \%)$ & \\
\hline \multicolumn{2}{|l|}{$\begin{array}{l}\text { Distance to RT facility, miles } \\
\text { Median (range) }\end{array}$} & $4.7(0-135)$ & $4.7(0-135)$ & $4.0(0-35)$ & \\
\hline \multirow[t]{5}{*}{$\mathrm{N}($ column \%) } & $<5$ & $586(50 \%)$ & $557(50 \%)$ & $29(57 \%)$ & .54 \\
\hline & $5-10$ & $254(22 \%)$ & $242(21 \%)$ & $12(23 \%)$ & \\
\hline & $10-30$ & $244(21 \%)$ & $235(21 \%)$ & $9(18 \%)$ & \\
\hline & $>30$ & $54(5 \%)$ & $53(5 \%)$ & $1(2 \%)$ & \\
\hline & Unknown & $32(3 \%)$ & $32(3 \%)$ & $0(0 \%)$ & \\
\hline \multirow[t]{7}{*}{ Year of diagnosis } & 2005 & $76(7 \%)$ & $75(7 \%)$ & $1(2 \%)$ & .53 \\
\hline & 2006 & $198(17 \%)$ & $191(17 \%)$ & $7(14 \%)$ & \\
\hline & 2007 & $222(19 \%)$ & $212(19 \%)$ & $10(20 \%)$ & \\
\hline & 2008 & $195(17 \%)$ & $185(16 \%)$ & $10(20 \%)$ & \\
\hline & 2009 & $221(19 \%)$ & $212(19 \%)$ & $9(18 \%)$ & \\
\hline & 2010 & $204(17 \%)$ & $191(17 \%)$ & $13(25 \%)$ & \\
\hline & 2011 & $54(5 \%)$ & $53(5 \%)$ & $1(2 \%)$ & \\
\hline
\end{tabular}

Abbreviations: BMI, body mass index; IBD, inflammatory bowel disease; RT, radiotherapy. ${ }^{a}$ Chi-square test for proportions between preoperative RT vs no preoperative RT. 
Preoperative RT for Rectal Cancer

\begin{tabular}{|c|c|c|c|c|c|}
\hline Variable & Category & $\begin{array}{l}\text { All Patients } \\
(n=1170)\end{array}$ & $\begin{array}{l}\text { Preoperative RT } \\
(n=1119)\end{array}$ & $\begin{array}{l}\text { No Preoperative } \\
\text { RT } \\
(n=51)\end{array}$ & $P$ Value $^{a}$ \\
\hline \multirow[t]{4}{*}{$\mathrm{BMI}$ at presentation, $\mathrm{kg} / \mathrm{m}^{2}$} & $<25$ & $360(31 \%)$ & $338(30 \%)$ & $22(43 \%)$ & \multirow[t]{4}{*}{.004} \\
\hline & $25-30$ & $448(38 \%)$ & $423(38 \%)$ & $25(49 \%)$ & \\
\hline & $>30$ & $333(28 \%)$ & $329(29 \%)$ & $4(8 \%)$ & \\
\hline & Unknown & $29(2 \%)$ & $29(3 \%)$ & $0(0 \%)$ & \\
\hline \multirow[t]{4}{*}{ ECOG performance status } & 0 & $942(81 \%)$ & $907(81 \%)$ & $35(68 \%)$ & \multirow[t]{4}{*}{$<.0001$} \\
\hline & 1 & $112(9 \%)$ & $106(9 \%)$ & $6(12 \%)$ & \\
\hline & $\geq 2$ & $18(1 \%)$ & $13(1 \%)$ & $5(10 \%)$ & \\
\hline & Unknown & $98(8 \%)$ & $93(8 \%)$ & $5(10 \%)$ & \\
\hline \multirow[t]{4}{*}{ Charlson comorbidity score } & 0 & $850(73 \%)$ & $820(73 \%)$ & $30(59 \%)$ & \multirow[t]{4}{*}{$<.0001$} \\
\hline & 1 & $202(17 \%)$ & $195(17 \%)$ & $7(14 \%)$ & \\
\hline & 2 & $78(7 \%)$ & $66(6 \%)$ & $12(24 \%)$ & \\
\hline & $\geq 3$ & $40(3 \%)$ & $38(3 \%)$ & $2(4 \%)$ & \\
\hline \multirow[t]{3}{*}{ Clinical TNM stage } & II & $401(34 \%)$ & $373(33 \%)$ & $28(55 \%)$ & \multirow[t]{3}{*}{.002} \\
\hline & III & $749(64 \%)$ & $728(65 \%)$ & $21(41 \%)$ & \\
\hline & Unable to stage & $20(2 \%)$ & $18(2 \%)$ & $2(4 \%)$ & \\
\hline \multirow{2}{*}{$\begin{array}{l}\text { History of connective tissue } \\
\text { disease }\end{array}$} & Yes & $7(1 \%)$ & $7(1 \%)$ & $0(0 \%)$ & \multirow[t]{2}{*}{.99} \\
\hline & No & $1163(99 \%)$ & $1112(99 \%)$ & $51(100 \%)$ & \\
\hline \multirow{2}{*}{$\begin{array}{l}\text { History of Crohn disease } \\
\text { or IBD }\end{array}$} & Yes & $15(1 \%)$ & $15(1 \%)$ & $0(0 \%)$ & \multirow[t]{2}{*}{.99} \\
\hline & No & $1155(99 \%)$ & $1104(99 \%)$ & $51(100 \%)$ & \\
\hline \multirow[t]{3}{*}{ Preoperative tumor fixation } & Yes & $144(12 \%)$ & $139(12 \%)$ & $5(10 \%)$ & \multirow[t]{3}{*}{.36} \\
\hline & No & $840(72 \%)$ & $799(71 \%)$ & $41(80 \%)$ & \\
\hline & Unknown & $186(16 \%)$ & $181(16 \%)$ & $5(10 \%)$ & \\
\hline \multirow{4}{*}{$\begin{array}{l}\text { Tumor distance from anal } \\
\text { verge, } \mathrm{cm}\end{array}$} & $<5$ & $342(29 \%)$ & $330(29 \%)$ & $12(24 \%)$ & \multirow[t]{4}{*}{.02} \\
\hline & $5-10$ & $654(56 \%)$ & $630(56 \%)$ & $24(47 \%)$ & \\
\hline & $>10$ & $111(10 \%)$ & $100(9 \%)$ & $11(21 \%)$ & \\
\hline & Unknown & $63(5 \%)$ & $59(5 \%)$ & $4(8 \%)$ & \\
\hline \multirow[t]{3}{*}{ Chemotherapy sequencing } & $\begin{array}{l}\text { Neoadjuvant only } \\
\text { Adjuvant only }\end{array}$ & $\begin{array}{c}241(20 \%) \\
21(2 \%)\end{array}$ & $\begin{array}{c}237(21 \%) \\
10(1 \%)\end{array}$ & $\begin{array}{c}4(8 \%) \\
11(21 \%)\end{array}$ & \multirow[t]{10}{*}{$<.0001$} \\
\hline & Both & $877(75 \%)$ & $865(77 \%)$ & $12(24 \%)$ & \\
\hline & No chemotherapy & $31(3 \%)$ & $7(1 \%)$ & $24(47 \%)$ & \\
\hline \multirow[t]{7}{*}{ Neoadjuvant chemotherapy } & FU & $517(44 \%)$ & $517(46 \%)$ & $0(0 \%)$ & \\
\hline & $\mathrm{FU} / \mathrm{LV}$ & $29(2 \%)$ & $28(2 \%)$ & $1(2 \%)$ & \\
\hline & CAPE & $402(34 \%)$ & $400(36 \%)$ & $2(4 \%)$ & \\
\hline & CAPOX & $30(3 \%)$ & $30(3 \%)$ & $0(0 \%)$ & \\
\hline & FOLFOX & $63(5 \%)$ & $50(4 \%)$ & $13(25 \%)$ & \\
\hline & Other & $77(6 \%)$ & $77(7 \%)$ & $0(0 \%)$ & \\
\hline & $\begin{array}{l}\text { No neoadjuvant } \\
\text { chemotherapy }\end{array}$ & $52(4 \%)$ & $17(1 \%)$ & $35(69 \%)$ & \\
\hline \multirow[t]{2}{*}{ Prior RT, pelvic } & Yes & $12(1 \%)$ & $6(<1 \%)$ & $6(12 \%)$ & \multirow[t]{2}{*}{$<.0001$} \\
\hline & No & $1158(99 \%)$ & $1113(99 \%)$ & $45(88 \%)$ & \\
\hline
\end{tabular}

Abbreviations: BMI, body mass index; IBD, inflammatory bowel disease; RT, radiotherapy.

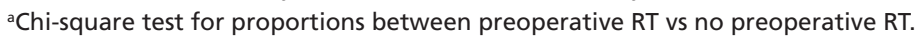

\section{Discussion}

Several large prospective trials have provided a clear role for RT in the management of locally advanced rectal cancer, with most recent data favoring the neoadjuvant approach. ${ }^{11,16,17}$ These data show that more than $90 \%$ of patients with stage II-III rectal cancer treated at NCCN Member Institutions are receiving guideline-concordant care with respect to RT. Furthermore, the stable use of neoadjuvant RT over the study period (2005-2012) attests to rapid 
implementation of changing guidelines at these centers after the publication of the German rectal trial in 2004 and incorporation into the NCCN Guidelines in 2005. These results differ from data derived from large cancer registries, including the California Cancer Registry and the SEER Program, which showed that fewer than $60 \%$ of patients with stage II-III rectal cancer treated in 1993-2003 and 20002006 were receiving RT as a part of definitive therapy. ${ }^{18,19}$ Moreover, only $63.8 \%$ of SEER patients who received RT in 2006 did so before surgery. Similarly, prior population-based analyses identified race and median income to be associated with nonconcordant care for rectal cancer, ${ }^{20,21}$ which may contribute to observed racial disparities in long-term survivors. ${ }^{22}$ This association was not seen in this analysis, suggesting that, with an increase in overall use of RT, the underuse noted in some racial and socioeconomic groups has decreased. Alternatively, these findings may also reflect a difference in the rates of guideline-concordant care between NCI-designated cancer centers and the medical community at large, although a SEER-based analysis evaluating NCIdesignated versus other centers found the difference between rates of concordant care with regard to RT for rectal cancer to be small..$^{23}$ Finally, the specific makeup of the study populations captured by the NCCN and SEER databases and somewhat different inclusion criteria used in different studies could also contribute to different results.

After adjusting for clinical factors associated with increased concern for therapy-related morbidity, including performance status, high Charlson score, and prior pelvic RT, the authors found that age, proximal tumor location, stage II disease, and BMI of $30 \mathrm{~kg} / \mathrm{m}^{2}$ or less were associated with omission of RT. Advanced age has been found in several studies to be associated with omission of (neo)adjuvant RT for rectal cancer. ${ }^{20,24,25}$ Patients older than 65 years are often underrepresented, and those older than 75 years were altogether excluded from randomized trials, thus limiting the ability to evaluate the risk/benefit ratio of RT for the elderly. However, nonrandomized data suggest that adjuvant therapy is associated with a survival advantage in patients with stage III rectal cancer older than 65 years. ${ }^{24,26}$ Attesting to a shift in the paradigm of caring for the older patient with rectal cancer, data reported here reveal

Table 2 Factors Associated With Not Receiving Preoperative RT

\begin{tabular}{|c|c|c|c|c|c|}
\hline Variable & Category & $\begin{array}{l}\text { Unadjusted Odds } \\
\text { Ratio }(95 \% \mathrm{Cl})\end{array}$ & $P$ Value & $\begin{array}{l}\text { Adjusted Odds } \\
\text { Ratio }(95 \% \mathrm{Cl})\end{array}$ & $P$ Value \\
\hline \multirow[t]{5}{*}{ Age at diagnosis, y } & $<45$ & $0.87(0.29,2.59)$ & $<.0001$ & $1.05(0.33,3.38)$ & .002 \\
\hline & $45-54$ & $1.14(0.47,2.79)$ & & $1.05(0.39,2.80)$ & \\
\hline & $55-64$ & Referent & & Referent & \\
\hline & $65-74$ & $0.81(0.29,2.27)$ & & $0.62(0.20,1.91)$ & \\
\hline & $\geq 75$ & $6.69(3.03,14.80)$ & & $4.43(1.70,11.5)$ & \\
\hline \multirow[t]{3}{*}{$\mathrm{BMI}$ at presentation, $\mathrm{kg} / \mathrm{m}^{2}$} & $<25$ & $4.86(1.68,14.10)$ & .008 & $4.23(1.25,14.30)$ & .03 \\
\hline & $25-30$ & $5.35(1.83,15.70)$ & & $5.22(1.56,17.50)$ & \\
\hline & $>30$ & Referent & & Referent & \\
\hline \multirow[t]{3}{*}{ ECOG performance status } & 0 & Referent & .0006 & Referent & .01 \\
\hline & 1 & $1.47(0.60,3.57)$ & & $1.12(0.36,3.42)$ & \\
\hline & $\geq 2$ & $9.97(3.37,29.50)$ & & $11.10(2.58,47.90)$ & \\
\hline \multirow[t]{2}{*}{ Clinical TNM stage } & II & $2.66(1.50,4.71)$ & .0008 & $2.27(1.16,4.43)$ & .02 \\
\hline & III & Referent & & Referent & \\
\hline \multirow[t]{3}{*}{ Tumor distance from anal verge, $\mathrm{cm}$} & $<5$ & Referent & .02 & Referent & .009 \\
\hline & $5-10$ & $1.05(0.52,2.12)$ & & $1.42(0.61,3.30)$ & \\
\hline & $>10$ & $3.03(1.30,7.07)$ & & $5.40(1.88,15.50)$ & \\
\hline \multirow[t]{2}{*}{ Prior RT, pelvic } & Yes & $24.70(7.70,79.70)$ & $<.0001$ & $23.90(4.34,1320)$ & .0003 \\
\hline & No & Referent & & Referent & \\
\hline
\end{tabular}

Abbreviations: BMI, body mass index; RT, radiotherapy. 
that a substantially higher percentage of patients older than 65 years are receiving guideline-directed RT than previously found in a SEER-Medicare analysis of patients treated in 1991-1996 (93\% vs 57\%). ${ }^{25}$ Further efforts are needed to define the risk/ benefit ratio of RT in the group older than 75 years.

Some controversy exists regarding whether neoadjuvant RT is needed for all patients with stage II-III rectal cancer. ${ }^{8}$ The absence of nodal involvement and proximal tumor location have emerged as favorable prognostic features conferring a low risk of local recurrence. Based on pooled data from 2551 patients enrolled on 3 North American rectal trials, intermediate-risk rectal cancer defined as $\mathrm{T} 1-\mathrm{T} 2 \mathrm{~N} 1$ or $\mathrm{T} 3 \mathrm{~N} 0$ carries a $6 \%$ to $8 \%$ risk of local recurrence, which is not significantly decreased by adjuvant RT. ${ }^{27}$ Tumor location was a significant predictor of local recurrence in the pre-TME era, but its significance is less clear in modern trials. The Dutch trial of preoperative hypofractionated RT (25 Gy in 5 factions) followed by TME confirmed that increasing distance from the anal verge was associated with better local control, with no statistically significant improvement with RT for tumors located farther than $10 \mathrm{~cm}$ from the anal verge (3.8\% vs $1.3 \% ; P=.17$ ). ${ }^{3}$ These considerations, together with concerns for RT toxicity and advances in systemic chemotherapy that have resulted in high radiographic response rates if given preoperatively, ${ }^{10}$ have led some clinicians to stray from the guidelines for this group of patients. Consistent with this, patients with stage II rectal cancer and proximal tumors treated at NCCN Member Institutions were less likely to receive RT. An ongoing randomized trial (ClinicalTrials.com identifier: NCT00462501) will further define a favorable subset of stage II-III rectal cancers that derives a small, if any, benefit from RT, and may lead to changes in future guidelines. In the meantime, forgoing guideline-directed RT outside of a clinical trial should only be done in a judicious manner. Omission of preoperative RT may be appropriate in certain clinical situations necessitating immediate surgical intervention, such as obstruction, perforation, or hemorrhage, in which case the patients are likely to receive postoperative RT. RT may also be omitted because of understaging at the time of diagnosis. Of note, patients who underwent postoperative RT and those with discordant clinical stage at diagnosis were excluded from the current analysis of factors associated with nonadherence to guidelines.

An interesting finding in this study was the inverse association between BMI and RT omission. Despite concerns that obesity may contribute to higher rates of complications from pelvic RT and subsequent surgery, which have been raised by some prior studies, obese patients in this cohort were found to be more likely to receive RT than their normal-weight and overweight counterparts. Given that obesity reduces the chances of sphincter preservation, ${ }^{28}$ one possibility is that a higher rate of RT use in this group may reflect efforts to increase the likelihood of sphincter preservation. Additionally, obesity has been linked by some to higher rates of local recurrence, ${ }^{29}$ and may therefore prompt more aggressive therapy for this population.

Another finding was that $58 \%$ of patients not receiving RT were not referred to a radiation oncologist. The decision not to refer is influenced by many factors, including patient preference and multiple clinical features. Although the low rate of referral to radiation oncology in this group may reflect the subset of patients at increased risk for RT toxicity or patients with proximal stage II tumors in whom the role of RT may be controversial, it also exposes a potential avenue for future interventions to further improve the rate of neoadjuvant RT for patients with locally advanced disease.

Like the previously published SEER-based analyses of preoperative RT in rectal cancer, this is an observational study. The NCCN Oncology Outcomes Database for Colorectal Cancers began accruing patients in 2005; therefore, data on long-term follow-up are limited. Consequently, the authors chose not to evaluate recurrence rates or survival. In contrast to SEER, the NCCN database contains more detailed information on medical comorbidities, medical history, chemotherapy administration, rectal tumor location, health insurance status, and, in some cases, reasons for omitting guideline-directed interventions. Therefore, the present analysis can provide an additional level of detail not available in the SEER database. 
Reyngold et al

Finally, a potential limitation of performing logistic regression on a limited number of events is overfitting of the data. Although the possibility that this approach resulted in one or more spurious associations cannot be excluded and warrants some caution in data interpretation, these findings are largely consistent with prior work on related subjects. Therefore, the results are compelling and warrant further consideration.

In summary, the high level of concordance with guideline-directed RT for locally advanced rectal cancer achieved at NCCN Member Institutions is encouraging. After adjusting for risk factors associated with increased RT toxicity, older, normal-weight to overweight patients and those with more favorable tumors based on tumor location and lymph node involvement were found to be less likely to receive neoadjuvant RT. Ongoing efforts to evaluate the benefits of neoadjuvant RT in the more favorable subgroup of locally advanced rectal cancers will be of value.

\section{Acknowledgments}

The authors would like to thank Eve Ferdman for editorial assistance.

\section{References}

1. Enker WE, Thaler HT, Cranor ML, et al. Total mesorectal excision in the operative treatment of carcinoma of the rectum. J Am Coll Surg 1995;181:335-346.

2. Folkesson J, Birgisson H, Pahlman L, et al. Swedish Rectal Cancer Trial: long lasting benefits from radiotherapy on survival and local recurrence rate. J Clin Oncol 2005;23:5644-5650.

3. Kapiteijn E, Marijnen CA, Nagtegaal ID, et al. Preoperative radiotherapy combined with total mesorectal excision for resectable rectal cancer. N Engl J Med 2001;345:638-646.

4. Peeters KC, Marijnen CA, Nagtegaal ID, et al. The TME trial after a median follow-up of 6 years: increased local control but no survival benefit in irradiated patients with resectable rectal carcinoma. Ann Surg 2007;246:693-701.

5. Camma C, Giunta M, Fiorica F, et al. Preoperative radiotherapy for resectable rectal cancer: a meta-analysis. JAMA 2000;284:10081015.

6. Douglass HO Jr, Moertel CG, Mayer RJ, et al. Survival after postoperative combination treatment of rectal cancer. $N$ Engl J Med 1986;315:1294-1295.

7. Prolongation of the disease-free interval in surgically treated rectal carcinoma. Gastrointestinal Tumor Study Group. N Engl J Med 1985;312:1465-1472.

8. Zoccali M, Fichera A. Role of radiation in intermediate-risk rectal cancer. Ann Surg Oncol 2012;19:126-130.
9. Gerard JP, Conroy T, Bonnetain F, et al. Preoperative radiotherapy with or without concurrent fluorouracil and leucovorin in T3-4 rectal cancers: results of FFCD 9203. J Clin Oncol 2006;24:4620-4625.

10. Chau I, Brown G, Cunningham D, et al. Neoadjuvant capecitabine and oxaliplatin followed by synchronous chemoradiation and total mesorectal excision in magnetic resonance imaging-defined poor-risk rectal cancer. J Clin Oncol 2006;24:668-674.

11. Sauer R, Becker $H$, Hohenberger W, et al. Preoperative versus postoperative chemoradiotherapy for rectal cancer. N Engl J Med 2004;351:1731-1740.

12. Benson AB III, Venook AP, Bekaii-Saab T, et al. NCCN Clinical Practice Guidelines in Oncology for Rectal Cancer. Version 2, 2014. Available at: NCCN.org. Accessed January 16, 2014.

13. Desch CE, McNiff KK, Schneider EC, et al. American Society of Clinical Oncology/National Comprehensive Cancer Network quality measures. J Clin Oncol 2008;26:3631-3637.

14. Charlson ME, Pompei P, Ales KL, et al. A new method of classifying prognostic comorbidity in longitudinal studies: development and validation. J Chronic Dis 1987;40:373-383.

15. Association AH. 2008 American Hospital Association Annual Survey of Hospitals. Chicago; 2008.

16. Roh MS, Colangelo LH, O'Connell MJ, et al. Preoperative multimodality therapy improves disease-free survival in patients with carcinoma of the rectum: NSABP R-03. J Clin Oncol 2009;27:5124-5130.

17. Park JH, Yoon SM, Yu CS, et al. Randomized phase 3 trial comparing preoperative and postoperative chemoradiotherapy with capecitabine for locally advanced rectal cancer. Cancer 2011;117:3703-3712.

18. Kuo I, Wong JH, Roy-Chowdhury S, et al. The use of pelvic radiation in stage II rectal cancer: a population-based analysis. Am Surg 2010;76:1092-1095.

19. Mak RH, McCarthy EP, Das P, et al. Adoption of preoperative radiation therapy for rectal cancer from 2000 to 2006: a Surveillance, Epidemiology, and End Results patterns-of-care study. Int J Radiat Oncol Biol Phys 2011;80:978-984.

20. Baxter NN, Rothenberger DA, Morris AM, et al. Adjuvant radiation for rectal cancer: do we measure up to the standard of care? An epidemiologic analysis of trends over 25 years in the United States. Dis Colon Rectum 2005;48:9-15.

21. Ayanian JZ, Zaslavsky AM, Fuchs CS, et al. Use of adjuvant chemotherapy and radiation therapy for colorectal cancer in a population-based cohort. J Clin Oncol 2003;21:1293-1300.

22. Morris AM, Wei $Y$, Birkmeyer NJ, et al. Racial disparities in late survival after rectal cancer surgery. J Am Coll Surg 2006;203:787794.

23. In H, Neville BA, Lipsitz SR, et al. The role of National Cancer Institute-designated cancer center status: observed variation in surgical care depends on the level of evidence. Ann Surg 2012;255:890-895.

24. Neugut AI, Fleischauer AT, Sundararajan V, et al. Use of adjuvant chemotherapy and radiation therapy for rectal cancer among the elderly: a population-based study. J Clin Oncol 2002;20:26432650.

25. Schrag D, Gelfand SE, Bach PB, et al. Who gets adjuvant treatment for stage II and III rectal cancer? Insight from Surveillance, Epidemiology, and End Results-Medicare. J Clin Oncol 2001;19:3712-3718.

26. Dobie SA, Warren JL, Matthews B, et al. Survival benefits and trends in use of adjuvant therapy among elderly stage II and 
Preoperative RT for Rectal Cancer

III rectal cancer patients in the general population. Cancer 2008;112:789-799.

27. Gunderson LL, Sargent DJ, Tepper JE, et al. Impact of $T$ and N stage and treatment on survival and relapse in adjuvant rectal cancer: a pooled analysis. J Clin Oncol 2004;22:1785-1796.

28. Howard JH, Gonzalez Q, Arnoletti JP, et al. Prognostic factors and preoperative radiation therapy associated with sphincter preservation in patients with resectable rectal cancer. Am J Surg 2008;195:239-243.

29. Meyerhardt JA, Tepper JE, Niedzwiecki D, et al. Impact of body mass index on outcomes and treatment-related toxicity in patients with stage II and III rectal cancer: findings from Intergroup Trial 0114. J Clin Oncol 2004;22:648-657. 